\title{
Conventions of dates and transliteration used in this volume
}

\section{City names}

Reflecting the troubled history of Russia is the changing name for the city of Peter the Great, founded as Saint Petersburg at the beginning of the eighteenth century. Following the outbreak of the First World War on 1 August 1914, it was renamed Petrograd, which sounded more patriotic. When Lenin died ten years later the city became Leningrad in his honour, and that is how it was known for over seventy years. Only with the fall of Communism in 1990 did it revert to its pre-1914 name of Saint Petersburg. In this book, the city is called by the name current at the time about which the author is writing.

This practice has been adopted throughout the text in relation to the names of other cities, which were also changed in the wake of the Revolution, although those changes have frequently been reversed since the demise of Communism.

\section{The calendar}

On 31 January 1918, Russia caught up with the rest of Europe and adopted the Gregorian calendar. Before this, dates in Russia were still established on the basis of the Julian calendar, which, by the twentieth century, was 13 days behind the Gregorian calendar and was frequently designated 'Old Style'. Dates given according to the Gregorian calendar were designated 'New Style'. Hence, the Bolshevik uprising took place on 25 October 1917 according to the Russian calendar (Old Style), but on 7 November according to Western usage (New Style). This is why it is called the October Revolution, but its anniversary is celebrated on 7 November. Throughout this volume, dates are given in accordance with the calendar in use at the time.

\section{System of transliteration}

The system of transliteration used in this volume is a slightly amended form of the GOST 52535.1-2006 (Passport 2010-) system, with the alteration that the double diacritical mark denoting the Russian soft sign has been omitted. Regarding Russian surnames, we have the general policy that, in the discursive context of an essay, names will be spelled in the form under which a writer or artist is 
commonly known in the Anglo-Saxon world, and in the bibliographic references in a scientific transliteration. E.g., Mayakovsky vs Maiakovskii, Tugendhold vs. Tugendkhol'd.

Some Christian names exist in multiple versions, e.g. Alexei and Alexey, Andrei and Andrey, Grigori and Grigory, Sergey and Sergei, Vasily, Vasilii and Wassily. However, usually in combination with a certain family name, one version is more common than the other. For example, Andrei Bely is more widespread than Andrey Belyi; Wassily Kandinsky is more frequently used than Vasily Kandinsky. This also extends to institutions, such as the State Tretyakov Gallery, Moscow, which uses this transliteration rather than Tret'iakov. 